\title{
Returns to grasshopper control on rangelands in southern Alberta
}

\author{
BLAIR A. SHEWCHUK AND WILLIAM A. KERR
}

\begin{abstract}
Blair A. Shewchuk was a research associate and William A. Kerr is a professor, Department of Economics, University of Calgary, Calgary, Canada.
\end{abstract}

\section{Abstract}

Economic injury levels (EILs) - the minimum density of insects that would be required to warrant treatment-were estimated for the 4 most common insecticides sprayed on grasshoppers in Alberta. The results indicate that under the assumed conditions spraying was rarely profitable unless the pests were at very high outbreak levels $\left(>30 / \mathrm{m}^{2}\right)$, the benefits of control lasted more than 1 season or the producers' treatment costs were substantially subsidized by a provincial government rebate program. Estimates vary considerably depending on several parameter values. The most important variables were the cost, life, and efficacy of treatments, the derived price of forage, and assumptions regarding grasshopper population dynamics.

\section{Key Words: economic injury, grasshoppers, pesticides}

This study compares 4 common methods of controlling rangeland grasshoppers in southern Alberta. Although a considerable literature exists on the control of grasshopper infestations of cereal grains and other high-priced crops, less research has been undertaken for rangeland forage (Pfadt and Hardy 1987, Davis et al. 1992). The paper's main objective is to estimate the minimum number of grasshoppers $/ \mathrm{m}^{2}$ required before control became profitable for beef cattle ranchers in 1985 and 1986. As ranchers received rebates of $50 \%$ on the cost of chemicals, it is postulated that this incentive made ranchers less tolerant of smaller infestations than if they had been required to pay the entire cost of pest management themselves. A model developed at New Mexico State University (Torell and Huddleston 1987, Torell et al. 1989) is used to estimate Economic Injury Levels (EILs) - the lowest densities of insects that would be profitable to control. The model is based on the biological research of Hewitt and Onsager $(1982,1983)$ most of which was conducted in Montana where cool-season grassland similar to southern Alberta's range is common. The 4 chemicals chosen for this study-Carbofuran, Deltamethrin, Chlorpyrifos and Carbaryl-represent $96 \%$ of all grasshopper chemical control used by farmers and ranchers participating in a government rebate program in Alberta in 198. - 2 1986. Statistics on the amount sprayed and on the cost of . ication are not normally collected on a province-wide basis. During these 2 years, however, the more than 5,000 agricultural producers who applied for financial assistance to help combat a large outbreak of grasshoppers were required to provide such information.

Carbofuran, Deltamethrin, Chlorpyrifos, and Carbaryl can be applied by ground based or aerial equipment as either a liquid spray or as a dry bait. Regardless of plant habitat, they are toxic to grasshoppers and kill by body contact, vapour ingestion, or direct ingestion. In the mid-1980s, 3 main species of grasshoppers were

\footnotetext{
This paper was partially funded by a Government of Alberta Farming for the Future grant.

Manuscript accepted 18 Mar. 1993
}

prevalent in southern Alberta-Melanoplus infantilis, Camnula pellucida and Melanoplus sanguinipes. It is assumed that the consumption of forage among species was homogeneous and the efficacy of each chemical was invariant with respect to grasshopper species.

\section{Economic Analysis of Grasshopper Control}

The economic model assumes that the primary loss from rangeland grasshoppers is decreased forage yield. It does not include such secondary losses such as reduced forage quality, migration to cropland and the nuisance cost associated with insect populations. Ignoring qualitative difference is particularly important since it means that the unit price of forage is the same whether pests are present or not. The model does not include the possible cost of "externalities," such as pollution, associated with spraying chemicals on rangelands.

Let $\mathrm{X}$ represent some known (or projected) level of pest infestation measured after the majority of grasshoppers are at the 4th instar stage but before an artifical control program is initiated:

$$
X_{u}=X^{r^{r} t}
$$

Population $X$ will grow or decline at rate $e^{r_{1}}$ if left untreated. Let $Z$ represent the new density of a grasshopper infestation after control and $\beta$ the efficacy of control. If:

$$
Z=(1-\beta) X \text { where } 0 \leq \beta \leq 1
$$

then:

$$
\mathrm{X}_{\mathrm{c}}=\mathrm{Ze}^{\mathrm{r}_{2} \mathrm{t}}
$$

the lower treated population is assumed to grow or decline at rate $\mathrm{e}^{\mathrm{r}_{2}}$.

Let $\mathrm{T}$ denote the expected number of years that benefits from a rangeland pest control program are expected to last. Over a growing season, the potential amount of forage saved by initiating control is estimated by taking the difference between the forage the uncontrolled grasshoppers would have destroyed $\left[D\left(X_{u}\right)\right]$ and the amount controlled pests eat or waste $\left[D\left(X_{c}\right)\right]$. The total amount of forage saved (S) over $T$ years is then

$$
S=\sum_{t=0}^{T}\left\{D\left[X_{u}(X, t)\right]-D\left[X_{c}(X, t)\right]\right\}
$$

where $t=0$ is the year treatment is applied.

Given an estimate of preventable damage from (4), the net present value of forage saved over the full life of the treatment $(T)$ is:

$$
\text { NPV }=\sum_{t=0}^{T} v S\left(X_{u}, X_{c}\right)(1+i)^{-t}-C
$$

where $v=$ the value of forage, $i=$ the interest rate and $C=$ the sum of 
fixed and variable treatment costs. If NPV is positive, the value of forage saved over the life of the treatment is greater than the cost of control, indicating a positive economic return. If it is negative, artificial control measures are not economically justified based solely on the value of forage that would otherwise be lost to grasshoppers.

The discrete-choice economic injury level is defined to be that level of grasshopper infestation $\left(X^{*}\right)$ where the net present value of forage saved over time is just equal to the cost of control:

$$
N P V=\sum_{t=0}^{T} v S\left[X_{u}\left(X^{*}, t\right), X_{c}\left(X^{*}, t\right)\right](1+i)^{-1}-C \equiv 0
$$

\section{Information Required for Analysis}

Information about the following variables is required for economic analysis of grasshopper control on rangeland: (1) pest population dynamics, (2) grasshopper survival rate, (3) efficacy of control, (4) forage destruction, (5) estimated forage value, (6) cost of treatment, (7) age of pest treated, (8) life of treatment, and (9) the discount rate. Each of these factors influences the economic injury level.

\section{Pest Population Dynamics}

Two growth rates are assumed: one for treated infestation and the other for untreated. The effects of immigration to and emigration from neighboring land are considered to cancel each other out. Entomologists have tried with little success to predict grasshopper outbreaks (Torell and Huddleston 1987). Numerous factors, including the weather, available food supply, and natural disease, affect the size of populations. Untreated populations are assumed to remain constant at level $X$ from season to season $\left(r_{1}=0\right)$. Treated populations are assumed to be reduced to a lower level and then to double every year for the duration of the control agent's life $\left(r_{2}=\right.$ $.695)$. This is because fewer grasshoppers are competing for available food at lower densities and because natural parasites are sometimes killed by chemical treatments.

\section{Grasshopper Survival Rate}

The natural daily survival rate of grasshoppers is a function of the size of their population as well as various external factors such as natural predators, disease and weather. The rate is assumed to be somewhat lower at higher densities-for example, approximately $98.5 \%$ for 4 fourth instar nymphs $/ \mathrm{m}^{2}$ but only $96.0 \%$ for $32 / \mathrm{m}^{2}$-because the competition for available food is greater (Onsager 1984). Paradoxically, the daily survival rate of treated infestations (i.e., those insects remaining after control agents are applied) is assumed to be higher than the survival rate of untreated infestations because the chemicals used to kill grasshoppers often
Table 1. Cost of insecticides in Alberta (CdnS).

\begin{tabular}{|c|c|c|c|c|}
\hline & \multicolumn{2}{|c|}{ Cost } & \multicolumn{2}{|c|}{ Participation } \\
\hline & 1985 & 1986 & 1985 & 1986 \\
\hline \multirow[b]{2}{*}{ Carbofuran } & \multicolumn{2}{|c|}{ — $\$$ / hectare- } & \multicolumn{2}{|c|}{-\% of farmers spraying - } \\
\hline & $\$ 5.30$ & 5.41 & 57 & 68 \\
\hline Deltamethrin & 10.15 & 10.34 & 22 & 15 \\
\hline Chlorpyfifos & 13.51 & 13.63 & 9 & 9 \\
\hline Carbaryl & 18.59 & 19.86 & 8 & 4 \\
\hline
\end{tabular}

[Crop Protection Branch, Alberta Agriculture]

kill the insects' natural enemies as well (Onsager 1983).

\section{Efficacy of Control}

Every treatment's effectiveness will vary depending on the temperature and precipitation when it is applied, as well as on terrain, vegetation and how uniformly it is sprayed (Torell and Huddleston 1987). In general, recommended insecticides applied under "acceptable conditions" can be expected to provide at least a $90 \%$ reduction in grasshopper infestations within a few days. Hence, $\beta$ is assumed to be equal to 0.9 .

\section{Forage Destruction}

An average grasshopper on cool-season grassland consumes 9, 22 , and $53 \mathrm{mgs}$ of forage per day in the fourth instar, fifth instar, and adult stages, respectively (Onsager 1983). Grasshopper populations in southern Alberta are similar to those on cool-season grasslands of Montana (Shewchuk 1991). Using these rates in conjunction with estimates of the average daily survival rate of grasshoppers, Torell and Huddleston's (1987) model calculates the average daily forage destruction rate, $D(X)$.

\section{Value of Forage}

The value of grass and forage can be assessed only indirectly. The derived value of forage will vary, depending on a number of factors including livestock prices, the cost of production, the quality of the rangeland, alternative forage sources and seasonal supply limitations. For western Canada, range is valued between $\$ 7.00$ and $\$ 11.00 /$ AUM (Shewchuk) 1991). A value of $\$ 10.00 / A U M$ is used for average conditions and sensitivity analysis was undertaken for seven $\$ 2.00$ increments from a minimum of \$4.00/AUM to $\$ 16.00 / A U M$. Ranchers are treated as price-takers. In other words, decisions they take about combating grasshopper infestations are not assumed to affect the value of AUMs in their region. Further, all lost forage is considered to have an opportunity costi.e., the plant life harvested by grasshoppers is assumed to have otherwise been used as an input to cattle production and, hence, to have a value measured in dollars per AUM.

Table 2. Economic injury levels measured in fourth instar grasshoppers $/ \mathrm{m}^{2}(100 \%$ chemical cost $/$ zero application cost $)$.

\begin{tabular}{|c|c|c|c|c|c|c|c|c|c|c|}
\hline \multirow{2}{*}{\multicolumn{2}{|c|}{$\begin{array}{l}\text { Value of forage } \\
\text { Life of treatment (yrs.) }\end{array}$}} & \multicolumn{3}{|c|}{ \$8/AUM } & \multicolumn{3}{|c|}{$\$ 10 / A U M$} & \multicolumn{3}{|c|}{ \$12/AUM } \\
\hline & & 1 & 2 & 3 & 1 & 2 & 3 & 1 & 2 & 3 \\
\hline \multicolumn{11}{|l|}{1985} \\
\hline $\begin{array}{l}\text { Carofuran } \\
\text { Deltamethrin } \\
\text { Chlorpyrifos } \\
\text { Carbaryl }\end{array}$ & $\begin{array}{l}\$ 5.38 / \text { ha } \\
\$ 10.28 / \text { ha } \\
\$ 13.68 / \text { ha } \\
\$ 18.43 / \text { ha }\end{array}$ & $\begin{array}{r}65 \\
* \\
* \\
*\end{array}$ & $\begin{array}{r}23 \\
72 \\
* \\
*\end{array}$ & $\begin{array}{r}13 \\
50 \\
* \\
*\end{array}$ & $\begin{array}{r}43 \\
* \\
*\end{array}$ & $\begin{array}{r}13 \\
51 \\
* \\
*\end{array}$ & $\begin{array}{r}6 \\
32 \\
53 \\
*\end{array}$ & $\begin{array}{r}32 \\
* \\
* \\
*\end{array}$ & $\begin{array}{r}6 \\
37 \\
60 \\
*\end{array}$ & $\begin{array}{r}4 \\
22 \\
39 \\
68\end{array}$ \\
\hline \multicolumn{11}{|l|}{1986} \\
\hline $\begin{array}{l}\text { Carbofuran } \\
\text { Deltamethrin } \\
\text { Chlorpyrifos } \\
\text { Carbaryl }\end{array}$ & $\begin{array}{l}\text { \$5.48/ha } \\
\$ 10.48 / \text { ha } \\
\$ 13.80 / \text { ha } \\
\$ 20.10 / \text { ha }\end{array}$ & $\begin{array}{r}68 \\
* \\
* \\
*\end{array}$ & $\begin{array}{r}25 \\
* \\
* \\
*\end{array}$ & $\begin{array}{r}13 \\
51 \\
* \\
*\end{array}$ & $\begin{array}{r}46 \\
* \\
* \\
*\end{array}$ & $\begin{array}{r}13 \\
53 \\
* \\
*\end{array}$ & $\begin{array}{r}8 \\
34 \\
56 \\
*\end{array}$ & $\begin{array}{r}32 \\
* \\
* \\
*\end{array}$ & $\begin{array}{r}8 \\
39 \\
61 \\
*\end{array}$ & $\begin{array}{r}4 \\
25 \\
41 \\
*\end{array}$ \\
\hline
\end{tabular}

EIL $>73$ grasshoppers $/ \mathrm{m}^{2}$. 
Table 3. Economic injury levels measured in fourth instar grasshoppers $/ \mathrm{m}^{2}(50 \%$ chemical cost/zero application cost).

\begin{tabular}{|c|c|c|c|c|c|c|c|c|c|c|}
\hline \multirow{2}{*}{\multicolumn{2}{|c|}{$\begin{array}{l}\text { Value of forage } \\
\text { Life of treatment (yrs.) }\end{array}$}} & \multicolumn{3}{|c|}{ \$8/AUM } & \multicolumn{3}{|c|}{ \$10/AUM } & \multicolumn{3}{|c|}{ \$12/AUM } \\
\hline & & 1 & 2 & 3 & 1 & 2 & 3 & 1 & 2 & 3 \\
\hline 1985 & & \multicolumn{9}{|c|}{$\ldots$ - Grasshoppers $/ \mathrm{m}^{2} \ldots$} \\
\hline
\end{tabular}

*EIL > 73 grasshoppers $/ \mathrm{m}^{2}$.

The cost of control varies depending on the type of agent used, the size of the area treated and the method of application. In addition, government rebates and other forms of public subsidies affect the cost actually borne by the producer. Data on the cost of grasshopper control is not normally collected in Canada. However, cost of control data was compiled for a provincial government rebate program in Alberta in 1985 and 1986 and is presented in Table 1. The values are averages based on data collected from more than 5,000 farmers and ranchers. The values represent the price of the insecticides only and do not include fixed treatment costs such as labour and equipment. Provincial survey of custom spraying in the region for the years 1985 and 1986 (Alberta Agriculture) as well as Madder and Stemeroff (1986) suggests a fixed cost of application equal to $\$ 10.00 /$ ha.

\section{Age of Pest Treated}

The amount of forage potentially saved from grasshopper consumption is a function of the stage in the grasshopper's life that treatment takes place. As the efficacy of treatment is not related to the age of the grasshopper, the optimal time to treat them is as soon as an identified economic threshold has been reached. Treatment is assumed to be initiated as pests reach the fourth instar level of development.

\section{Life of Treatment}

There is no conclusive evidence about how long treatments are likely to offer measurable benefits. Estimates range from 1 to 5 years (Pfadt and Hardy 1987). The 4 chemicals examined have an expected life of 1 to 3 years.

\section{Discount Rate}

In 1985 and 1986, the prime lending rate in Canada averaged $10.58 \%$ and $10.52 \%$, respectively. The real rates of interest were $6.63 \%$ and $6.43 \%$. During the same period, most Canadian farmers received new, short-term loans from banks at a nominal interest rate of approximately $11.5 \%$. When adjusted for inflation, the real rate was between $7.0 \%$ and $8.0 \%$. A discount rate of $7 \%$ is used in this study. Sensitivity analysis was conducted for discount rates of $5 \%, 10 \%$, and $15 \%$.

\section{Economic Injury Levels}

Tables 2 and 3 present estimated economic injury levels based on varying only the price of forage and the number of years the treatment is expected to be effective: treatment efficiency $=90 \%$; the discount rate $=7 \%$; the untreated pest population's annual growth rate is constant, the treated population doubles each year; control is initiated at the start of the fourth instar stage and natural predators are assumed to be killed by the insecticides. Further, the unrealistic assumption is made that there is no cost of application. The model's results suggest that under the assumed conditions it

Table 4. Economic injury levels measured in fourth instar grasshopper $/ \mathbf{m}^{2}$.

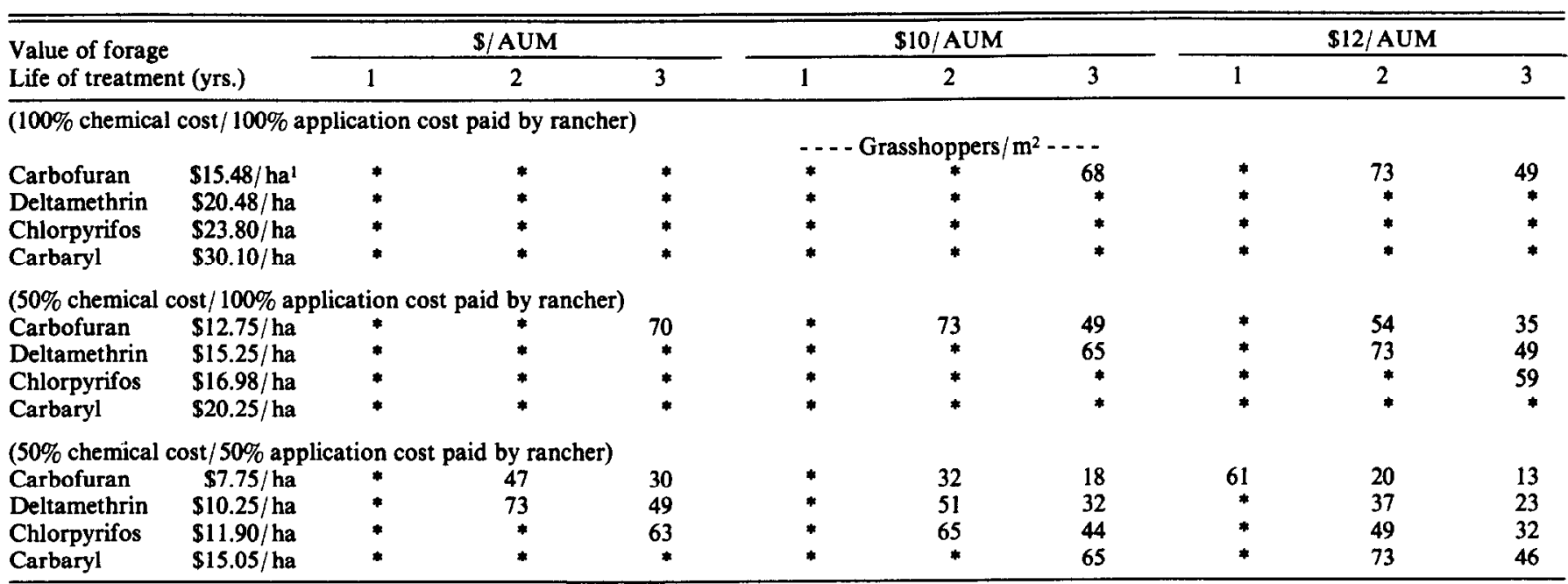

EIL > 73 grasshoppers $/ \mathrm{m}^{2}$.

INote: The per/ha costs reported here are the sum of chemical and application cost. 
would rarely be profitable for ranchers to control grasshoppers infesting forage unless pests were at extremely high outbreak levels - more than 50 grasshopper $/ \mathrm{m}^{2}$, the benefits from spraying lasted more than 1 season, or the producer's treatment costs were substantially subsidized. Even in this unrealistic example-with the cost of application assumed to be zero-the price of chemicals must be reduced by $50 \%$ (e.g., through a government rebate program) before all 4 agents are worth spraying on medium to low densities of grasshoppers infesting rangelands.

Table 4 compares 3 different categories of insecticide treatment: (1) $100 \%$ of the chemical cost plus $100 \%$ of the application cost paid by the rancher; (2) $50 \%$ of the chemical cost plus $100 \%$ of the application cost paid by the rancher; and (3) $50 \%$ of the chemical cost plus $50 \%$ of the application cost paid by the rancher. In each category, 3 different forage values and periods of treatment effectiveness are considered. All other parameters remain fixed as before. Under a program similar to the one implemented by the government of Alberta where farmers were reimbursed for $50 \%$ of the cost of the chemical, Carbaryl is never profitable at infestation levels less than $73 / \mathrm{m}^{2}$. Chlorpyrifos and Deltamethrin are profitable only at high densities, when the price of forage is high and when the benefits of control are considered to last at least 3 years. Carofuran is profitable at somewhat lower economic injury levels. None of the agents is profitable if a treatment's effectiveness is limited to a single season.

Table 5 summarizes the results of sensitivity analysis undertaken for the least expensive and most commonly used insecticide, Carbofuran. A complete set of results can be found in Shewchuk (1991). Average conditions produce an economic injury level of 32 fourth instar grasshoppers $/ \mathrm{m}^{2}$ while the various sensitivity analyses produce economic injury level estimates ranging from 4 to 73 . The most important factors affecting the economic injury levels are the derived value of the forage saved by control, the cost, life, and efficacy of treatment and the various underlying biological assumptions related to pest population dynamics. The choice of a discount rate and the exact age of the pest when treated are less crucial. It is noteworthy that the length of time benefits from control are assumed to continue is critical at first but virtually irrelevant after the third season. It is also important to note that economic injury levels are very high when chemical effectiveness falls below $80 \%$. This suggests that alternative technologies such as biological agents, even if low priced, would not be economically justified unless they performed almost as quickly and effectively as chemical agents.

Finally, if ranchers delay too long to initiate control, it may not be rational to spray at all. Although very high economic injury levels exist for populations already halfway through the adult stage, these are probably misleading if 2 or more years of benefits are assumed because population allowed to develop this far will have laid a sizable number of eggs in the ground for next season. When benefits from a chemical are reduced to a single season under such circumstances, treatment is not profitable (Table 5).

There is a common perception that the economic returns from the use of pesticides are often high. In a recent survey of the relevant literature, Stemeroff and Culver (1987) found that for each dollar spent on treatment, benefits range from a loss of $\$ 1.02$ to a gain of $\$ 13.85$. The majority of expenditures on insecticides surveyed in Canada produce positive economic returns of at least 3 to 1 . A number of crops were studied-fruit, corn, cotton, potatoes and onions-in several provinces and states. Forage, however, was not included. Given that the profitability of control varies widely from crop to crop, it should not be automatically assumed that killing grasshoppers infesting pasture is economic. The results of this study support the findings of other studies of grasshopper control on rangeland (Torell et al. 1989, Davis et al. 1992) that

Table 5. Economic injury levels for carbofuran measured in fourth instar grasshoppers $/ \mathbf{m}^{2}$ (Sensitivity Analysis-Various Conditions)

\begin{tabular}{|c|c|c|c|}
\hline & 4th Instar & & Instar \\
\hline -Gras & ppers $/ m^{2}-$ & -Grassho & $/ \mathrm{m}^{2}$ \\
\hline Average conditions ${ }^{1}$ & 32 & & \\
\hline $\begin{array}{l}\text { Forage } \\
\qquad \text { \$6/AUM }\end{array}$ & 73 & $\begin{array}{r}\text { Annual growth rates } \\
\text { (Untreated population) }\end{array}$ & \\
\hline S8/AUM & 46 & Decrease by Half & 49 \\
\hline \$10/AUM & 32 & Constant & 32 \\
\hline \$12/AUM & 20 & Double & 18 \\
\hline \$14/AUM & 15 & (Treated population) & \\
\hline \$16/AUM & 8 & Constant & 25 \\
\hline & & Double & 32 \\
\hline & & Triple & 37 \\
\hline Discount Rate & & Treatment Efficacy & \\
\hline $5 \%$ & 30 & $99 \%$ & 13 \\
\hline $7 \%$ & 32 & $95 \%$ & 18 \\
\hline $10 \%$ & 32 & $90 \%$ & 33 \\
\hline $15 \%$ & 32 & $85 \%$ & 39 \\
\hline & & $80 \%$ & 51 \\
\hline & & $75 \%$ & 65 \\
\hline & & $70 \%$ & * \\
\hline
\end{tabular}

Treatment Life

$\begin{array}{lr}1 \text { year } & * \\ 2 \text { years } & 32 \\ 3 \text { years } & 18 \\ 4 \text { years } & 18 \\ 5 \text { years } & 18\end{array}$

Treatment Cost

$\$ 3.75 /$ ha

$\$ 5.00 /$ ha

$\$ 6.25 /$ ha

$\$ 7.75 /$ ha

$\$ 8.75 /$ ha

$\$ 10.00 /$ ha

$\$ 11.25 / \mathrm{ha}$

$\$ 12.50 /$ ha

$\$ 12.75 /$ ha

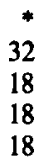

18

Average Conditions: Forage $=\$ 10 /$ AUM; Discount Rate $=7 \%$; Treatment Life $=2$ years; Treatment Cost $=\$ 7.75$; Annual Untreated Growth Rate $=$ Constant; Annual years; Treatment Cost $=\$ 7.75 ;$ Annual Untreated Growth Rate $=$ Constant; Annual
Treated Growth Rate $=$ Double; Treatment Efficacy $=90 \%$; Control Initiated Treated Growth Rate = Double; Treatment Efficacy
Before Fourth Instar Stage; Predators Assumed Killed.

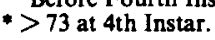

economic control would not be possible except at extreme outbreak levels or very high forage values. Whenever costs are substantially subsidized, individual agricultural producers are likely to perceive the true benefits of treatment differently than society. In the words of Torell et al. (1989) under such circumstances: "A rancher would like to see much lower densities of rangeland pests controlled than the tax-paying public would care to pay for" ( $p$. 1292). To the extent that the assumptions made in this investigation are valid, the results suggest that government rebates should not apply for most rangeland areas of Canada unless secondary benefits such as a reduction in the spread of grasshoppers to higher value crops, etc., are considered.

\section{Literature Cited}

Alberta Agriculture. 1988. Custom rates survey-fertilizer and herbicide applications and grain seeding: 1985 to 1987. Statistics Branch, Edmonton.

Davis, R.M., M.D. Skold, J.S. Berry, and W.P. Kemp. 1992. The economic threshold for grasshopper control on public rangelands. J. Agr. Resource Econ. 17:56-65.

Hewitt, G.B., and J.A. Onsager. 1982. A method for forecasting potential losses from grasshoppers feeding on northern mixed prairie forages. $J$. Range Manage. 35:53-57. 
Hewitt, G.B., and J.A. Onsager. 1983. Control of grasshoppers on rangeland in the United States-a perspective. J. Range Manage. 36:202-207. Madder, D.J., and M. Stemeroff. 1986. The economics of insect control on wheat, corn and canola in Canada: 1980-85. Ent. Soc. of Canada, Ottawa.

Onsager, J. 1983. Relationships between survival rate, density, population trends and forage restriction by instars of grasshoppers. Environ. Ent. 12:1099-1102.

Onsager, J. 1984. A method for estimating economic injury levels for control of rangeland grasshoppers with Malathion and Carbaryl. J. Range Manage. 37:200-203.

Pfadt, R.E., and D.M. Hardy. 1987. A historical look at rangeland grasshoppers and the value of grasshopper control programs. p. 183-195. In: J. Capinera (ed.), Integrated Pest Management on rangeland: $A$ shortorass prairie perspective. Westview Press, Boulder.
Shewchuk, B.A. 1991. An economic analyses of some of the most common methods used to control rangeland grasshoppers in Southern Alberta. Unpublished M.Ec. Res. Proj., Dep. Econ., Univ. Calgary.

Stemeroff, M., and D. Culver. 1987. Economic returns to pest control technologies in Canada. Can. Farm. Econ. 21:29-36.

Torell, L.A., J.H. Davis, E.W. Huddleston, and D.C. Thompson. 1989. Economic injury levels for interseasonal control of rangeland insects. J. Econ. Ent. 82:1289-1294.

Torell, L.A., and E.W. Huddleston. 1987. Factors affecting the economic threshold for control of rangeland grasshoppers. p. 377-396. In: J. Capinera (ed.), Integrated Pest Management in rangeland: A shortgrass prairie perspective. Westview Press, Boulder. 